CASSOWARY volume 5 (1) Januari 2022: 48 - 57

ISSN : 2614-8900

E-ISSN : 2622-6545

Program Pascasarjana Universitas Papua, https://pasca.unipa.ac.id/

\title{
Pemetaan sebaran dan kondisi tutupan terumbu karang di Desa Gili Gede Indah, Lombok Nusa Tenggara Barat (studi kasus: Gili Gede, Gili Layar, Gili Asahan)
}

\author{
Lalu Auliya Akraboe Littaqwa ${ }^{1 *)}$, Gagassage Nanaluih De Side ${ }^{1)}$ \\ 1)Program Studi Teknik Lingkungan Fakultas Teknik, Universitas Nahdlatul Ulama \\ Nusa Tenggara Barat, Jalan Pendidikan No. 6 Kota Mataram, Indonesia \\ *Email: lalu.auliya@gmail.com
}

Disubmit: 12 November 2021, direvisi: 10 Januari 2022, diterima: 25 Januari 2022

Doi: https://doi.org/10.30862/casssowary.cs.v5.i1.127

\begin{abstract}
Coral reefs are one of the potential marine resources in Indonesia, especially on the island of Lombok which needs to be taken into account. So that the mapping of the distribution and extent of coral reefs is needed in developing the potential of marine and coastal resources. One of the small islands that have potential is on the west side of the island of Lombok, namely in Gili Gede Indah Village, Gili Asahan, and Gili Layar. The ecological and economic functions of the coral reef ecosystem will run well if the condition of the coral reef is in a healthy condition. The method used to calculate the distribution is using Sentinel 2A satellite imagery with a spectral resolution of $30 \mathrm{~m}^{2}$ with a supervised method of image data processing using Google Earth Engine (GEE). in situ observational physics parameter data. coral reefs were carried out at a depth of $3.8-$ 6 meters. The results of observations and analysis of coral reef cover area on Gili Gede $17.84 \mathrm{~km}^{2}$, Gili Layar $9.72 \mathrm{~km}^{2}$ and Gili Asahan $11.91 \mathrm{~km}^{2}$. Confusion matrix interpretation results are Gili Gede 82\%, Gili Layar 70.3\%, and Gili Asahan 88.5\%. While the percentage of live coral reefs in the three dyke is $9.2-26.2 \%$. This percentage shows the criteria and conditions of low to moderate coral reefs. Although the condition of the physicochemical parameters in the three dyke was classified as good, namely DO $8.4-$ $8.7 \mathrm{mg} / \mathrm{l}$, salinity $31-32 \%$, temperature $29.6-30.2^{\circ} \mathrm{C}$, sea water clarity to $100 \%$. Coral damage due to fishing and tourism activities.
\end{abstract}

Keywords: remote sensing, coral reef ecosystem, gili gede indah

\section{PENDAHULUAN}

Ekosistem terumbu karang
memiliki banyak peranan selain mempunyai fungsi ekologis, ekosistem terumbu karang juga berfungsi sebagai pelindung pantai dari ancaman abrasi juga sebagai penyedia senyawa-senyawa penting untuk bahan makanan. Terumbu karang merupakan salah satu potensi sumber daya laut di Indonesia khususnya di Pulau Lombok yang patut diperhitungkan. Sehingga pemetaan sebaran dan luasan terumbu karang sangatlah dibutuhkan dalam pengembangan potensi sumber daya laut dan pesisir. Mengingat terumbu karang yang semakin lama semakin memprihatinkan dan harusnya menjadi 
sorotan kita untuk saat ini dan kedepannya.

Wilayah pesisir Lombok memiliki potensi sumberdaya alam yang sangat besar. Lombok menjadi salah satu kawasan penyangga untuk pengembangan budidaya di Indonesia bagian tengah. Pulau Lombok memiliki banyak pulau-pulau kecil. Pulau Lombok memiliki panjang garis pantai cukup luas yaitu sekitar $423 \mathrm{~km} 2$. Salah satu pulau-pulau kecil yang memiliki potensi yaitu di sisi barat pulau Lombok yaitu di Desa Gili Gede Indah yaitu Gili Gede, Gili Asahan, dan Gili Layar.

Fungsi ekologi dan ekonomi dari ekosisitem terumbu karang akan berlangsung baik apabila kondisi terumbu karang tersebut dalam kondisi sehat, hasil pemantauannya di Gili Gede pada tahun 2010, mengatakan kondisi terumbu karang di Gili Gede pada tahun tersebut dalam kondisi sedang yaitu $25 \%$ - 49,9\%. Dimana saat ini dengan kemajuan teknologi yang berkembang pesat eksplorasi Kawasan wisata oleh wisatawan sudah sangat tinggil.

Selain itu pula, kondisi hidrooseanografi merupakan faktor penting dalam keberlangsungan hidup ekosistem terumbu karang. antara lain salinitas, suhu permukaan laut, arus gelombang pasang surut, serta faktor meteorologis dan aktivitas manusia di darat seperti pembuangan sampah sembarangan atau pembuangan limbah juga dapat memberi pengaruh terhadap kondisi wilayah perairan laut dan ekosistem terumbu karang2. Potensi ekosistem terumbu karang di Indonesia khususnya di Pulau Lombok Cenderung mengalami penurunan kondisi.

Penginderaan jarak jauh sinar tampak (visible remote sensing) merupakan penginderaan jarak jauh yang menggunakan spektrum sinar tampak yang memiliki panjang gelombang sekitar 400-700 $\mathrm{nm}$.
Penginderaan jauh sinar tampak ini sangat penting di bidang kelautan. Penginderaan jauh sinar tampak dari seluruh jenis spekrtum gelombang elektromagnetik yang ada dapat menembus air laut hingga kedalaman tertentu. Dengan menggunakan penginderaan jauh sinar tampak, kita dapat mendeteksi atau mengukur bendabenda atau organisme yang berada di bawah permukaan air laut seperti fitoplankton, lamun, terumbu karang dan jenis substrat dasar perairan dangkal.

Kesediaan data yang akurat dan informasi mengenai luasan dan kondisi terumbu karang menjadi hal penting dalam upaya mencegah kerusakan ekosistem terumbu karang menjadi semakin berkembang dan menjadi dasar dalam pengelolaan pesisir dan pulaupulau kecil serta wisata berkelanjutan. Oleh karena itu pemanfaatan teknologi penginderaan jarak jauh menggunakan citra satelit dan pemantauan langsung dilapangan untuk mengetaui sebaran, luasan, dan kondisi terumbu karang sangat diperlukan di Gili Gede, Gili Layar dan Gili Asahan yang sudah terseksplor.

\section{MATERI DAN METODE}

\section{Sebaran dan Luasan Ekosistem Terumbu Karang}

Pemilihan lokasi penelitian didasarkan atas pertimbangan bahwa Desa Gili Indah yaitu Gili Gede, Gili Layar, dan Gili Asahan memiliki potensi terumbu karang dengan keanekaragaman jenis biota yang tinggi. Penelitian hanya difokuskan pada perairan laut dangkal yang terdapat terumbu karang saja. Penelitian dilakukan dengan dua tahapan yakni Pengolahan citra satelit menggunakan Google Earth Engine (GEE) dan pemantauan kondisi riil dilapangan. Citra satelit yang digunakan 
adalah Sentinel 2A dengan resolusi spectral $30 \mathrm{~m}^{2}$. Penggunaan metode analisis Supervised (analisis terbimbing). Pengolahan citra dengan pembentukan citra komposit untuk mendapatkan objek pada perairan agar lebih jelas. Penguatan respon spektral terumbu karang menggunakan metode transformasi Lyzenga. Tahapan pengolahan dengan Algoritma Lyzenga pada masing-masing citra yang telah dikoreksi geometrik dan radiometrik untuk mendapatkan identifikasi objek perairan laut dangkal ${ }^{7}$.

\section{Kondisi Terumbu Karang}

Pemantauan kondisi riil sekaligus memvalidasi di lapangan terumbu karang menggunakan metode Line Intercept Transect (LIT) dengan membentangkan meteran sepanjang $50 \mathrm{~m}$ dikombinasikan dengan Underwater Visual Census (UVC). Pencatatan dilakukan di Gili Gede, Gili Asahan dan Gili Layar pada satu titik pemantauan dengan panjang garis transek 50 meter. Pencatatan ekosistem terumbu karang menggunakan sabak dengan ketentuan lifeform karang berdasarkan kode-kode identifikasi ${ }^{8}$.

Masing-masing kategori bentuk pertumbuhan terumbu karang dihitung dengan rumus sebagai berikut:
Angka (persentase)tutupan

$=\frac{\text { Panjang total suatu kategori biota }}{\text { panjang total transek }} \times 100 \%$

Seluruh kategori bentuk pertumbuhan terumbu karang dihitung dengan rumus:

$$
\begin{aligned}
& \text { Persentase tutupan } \\
& =\frac{\text { Panjang tot. sel. kat.TK hidup }}{\text { panjang total transek }} \times 100 \%
\end{aligned}
$$

Tabel 1. Kriteria Penilaian Terumbu Karang

\begin{tabular}{ll}
\hline $\begin{array}{l}\text { Persentase } \\
\text { Tutupan }\end{array}$ & $\begin{array}{l}\text { Kriteria } \\
\text { Penilaian }\end{array}$ \\
\hline $0-24,9 \%$ & Rendah \\
$25-49,9 \%$ & Sedang \\
$50-74,9 \%$ & Baik \\
$75-100 \%$ & Baik Sekali \\
\hline
\end{tabular}

\section{Pengukuran Parameter Lingkungan Perairan}

Untuk pengukuran parameter fisika-kimia air dilakukan secara insitu pada tiap stasiun dengan masing-masing dilakukan pada setiap stasiun penelitian. Parameter-parameter lingkungan perairan yang diukur dipaparkan pada Tabel 2.

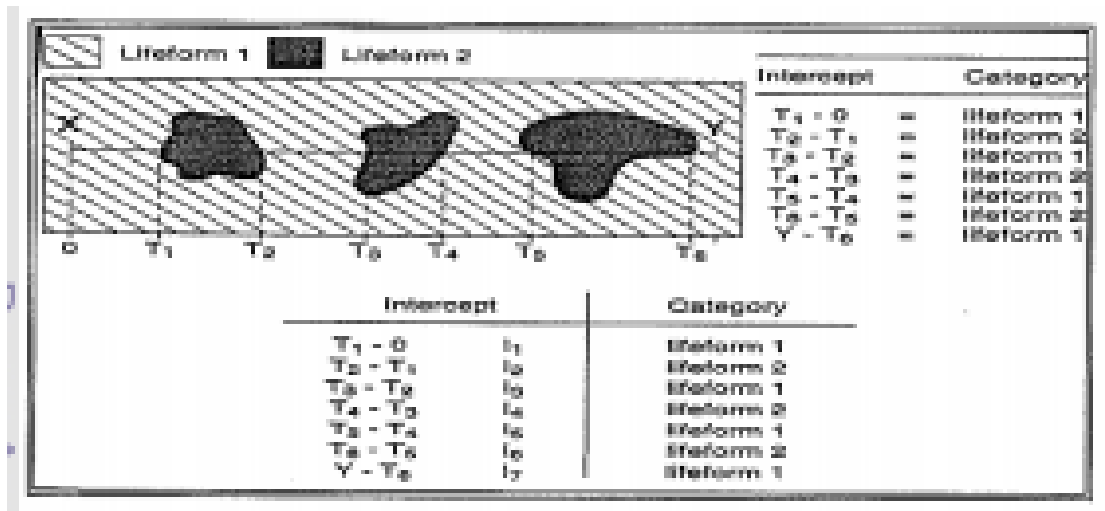

Gambar 1. Cara Pencatatan Data Koloni Karang dengan Metode Transek Garis 
Tabel 2. Parameter Lingkungan yang diukur

\begin{tabular}{lllll}
\hline No & Parameter & Satuan & Alat & Pengukuran \\
\hline 1 & Suhu & ${ }^{\circ} \mathrm{C}$ & Thermometer & In situ \\
2 & Refraktometer & $\%$ oo & Refraktometer & In Situ \\
3 & Kecepatan arus & $\mathrm{m} / \mathrm{s}$ & Flouting Droudge & In Situ \\
4 & Oksigen Terlarut & $\mathrm{ppm}$ & DO Meter & In Situ \\
5 & Kecerahan & $\%$ & Sechi disck & In Situ \\
6 & Kedalaman & $\mathrm{m}$ & & In Situ \\
\hline
\end{tabular}

\section{HASIL DAN PEMBAHASAN}

\section{Luasan Terumbu Karang}

Pengamatan luasan tutupan terumbu karang menggunakan data citra satelit Sentinel-2 MSI: MultiSpectral Instrument, Level-2A. Sentinel-2 adalah misi pencitraan multi spektral yang beresolusi tinggi yang mendukung pemantauan pengamatan jalur air dalam dan wilayah pesisir. Pengolahan dan analisis menggunakan Google Earth Engine (GEE). Setelah itu dilakukan koreksi geometri untuk melihat besarnya kesalahan hasil interpretasi. Tahap terakhir yang dilakukan selanjutnya adalah uji akurasi dengan menggunakan confusion matrix dan nilai koefisien Kappa. Uji akurasi ini dilakukan pada level 2 dan level 3 untuk melihat hasil yang optimum dari masing-masing algoritma machine learning yang digunakan dan melihat sebaran terumbu karang

Terumbu karang dapat

ditemukan di perairan dangkal yang jernih. Satelit Sentinel 2A memiliki sensor yang dapat mendeteksi karakteristik perairan dangkal dengan memanfaatkan saluran/kanal biru dengan panjang gelombang $0,450-0,52 \mu \mathrm{m}$ dan saluran/kanal hijau dengan panjang gelombang 0,52-0,60 $\mu \mathrm{m}$. Namun, untuk mengetahui kondisi dan tingkat kerusakan terumbu karang, pendeteksian dengan citra satelit tidaklah cukup sehingga diperlukan pengamatan secara langsung melalui aktivitas penyelaman. Pada umumnya, kondisi terumbu karang dapat dilihat dengan mengukur presentase tutupan karang hidup (living coral coverage).

Sebaran terumbu karang pada pengolahan citra satelit sentinel 2A dapat dilihat dengan warna merah muda. Ada beberapa kelas yang dilakukan selain terumbu karang. Pasir berwarna putih, lamun berwarna kuning, dan vegetasi berwarna hijau.

Tabel 3. Luasan Terumbu Karang dan ekosistem lainnya menggunakan Citra Satelit

\begin{tabular}{llll}
\hline \multicolumn{1}{c}{ Luas Kategori } & \multicolumn{1}{c}{$\begin{array}{c}\text { Gili Gede } \\
\mathbf{k m}^{\mathbf{2}}\end{array}$} & \multicolumn{1}{c}{$\begin{array}{c}\text { Gili Layar } \\
\mathbf{k m}^{\mathbf{2}}\end{array}$} & $\begin{array}{c}\text { Gili Asahan } \\
\mathbf{k m}^{\mathbf{2}}\end{array}$ \\
\hline Pasir & 67,74 & 0,98 & 5,98 \\
Terumbu Karang & 17,84 & 9,72 & 11,91 \\
Lamun & 22,56 & 0,75 & 1,24 \\
Vegetasi & 234,26 & 36,43 & 89,54 \\
Luas Area & $312 \mathrm{Ha}$ & $55 \mathrm{Ha}$ & $110 \mathrm{Ha}$ \\
\hline
\end{tabular}


Dari hasil interpretasi data citra dengan 4 kelas yaitu pasir, terumbu karang, lamun, dan vegetasi didapat hasil luasan terumbu karang di Gili Gede yaitu $17,84 \mathrm{~km}^{2}$, Gili Layar yaitu $9,72 \mathrm{~km}^{2}$, dan Gili Asahan yaitu 11,91 km².

\section{Hasil pengolahan citra satelit Sentinel}

2A

Hasil uji akurasi citra satelit sentinel menggunakan perhitungan confussion matrix pada perairan Gili Gede Indah. Pada perairan Gili Gede (Gambar 1A), terlihat nilai confussion matrix sebesar 0,82 atau $82 \%$. Sedangkan pada perairan Gili Layar (Gambar 1B) nilai confussion matrix sebesar 0,703 atau 70,3\% dan pada Gili Asahan (Gambar 1C) nilai confussion matrix sebesar 0,88 atau $88 \%$. Nilai interpretasi ketiga tersebut di atas $70 \%$ yang berarti tingkat kearutannya sangat tinggi. Menurut Semedi, dkk. 2019 Hasil uji akurasi citra satelit sentinel menggunakan perhitungan confussion matrix pada perairan Pulau Sempu memiliki nilai keakuratan mencapai 70,52\%. Hasil ground check menunjukkan bahwa nilai keakuratan dari citra satelit sentinel 2 sangat tinggi nilai kebenarannya lebih dari $70 \%$.

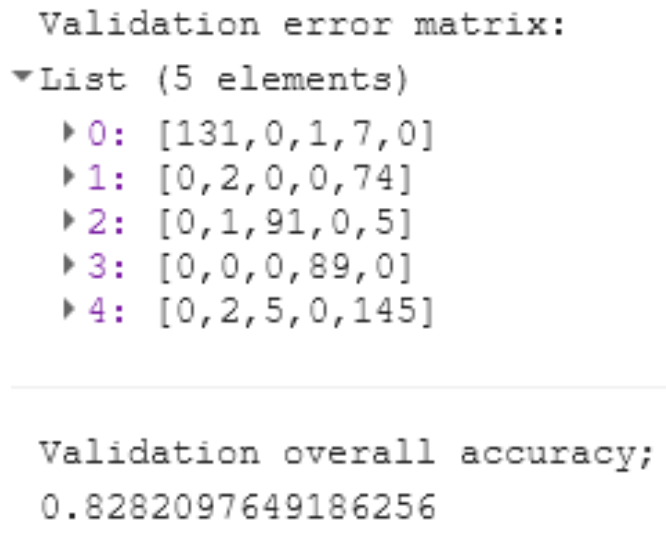

\subsection{6}

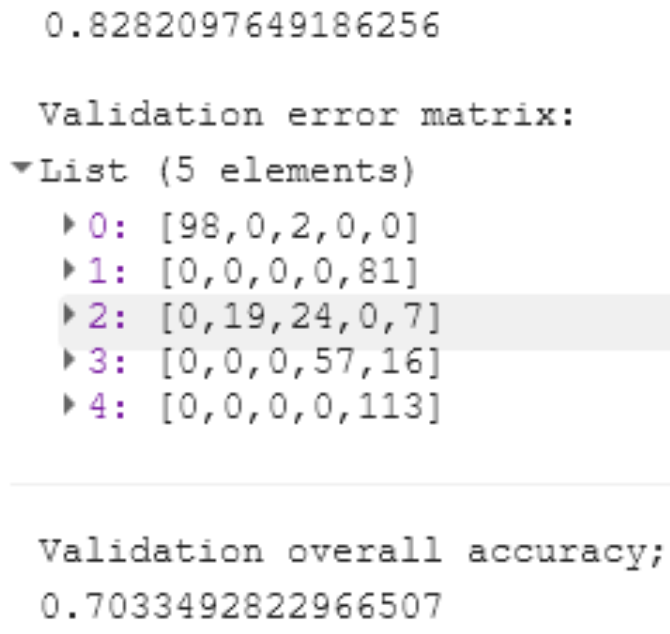




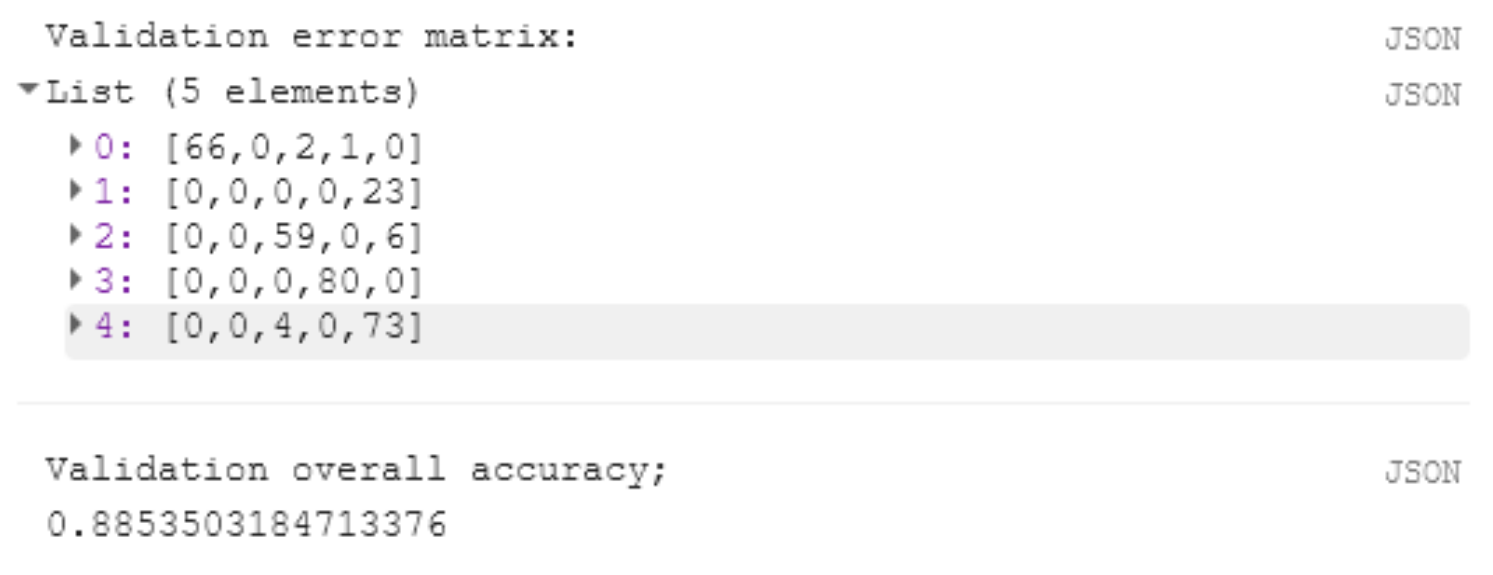

\subsection{6}

Gambar 2. Hasil Overall Accuracy Gili Gede, Gili Layar, dan Gili Asahan

\section{Kondisi Tutupan Terumbu Karang}

Pengukuran tutupan karang hidup pada perairan Gili Gede Indah dilalukan pada pukul 09.20 hingga pukul 14.10. Pengukuran di setiap gili dilakukan pada satu titik pengambilan sampel saja karena keterbatasan waktu. Tutupan terumbu karang di perairan Gili Gede dalam kondisi rendah hingga sedang dari hasil pengamatan.

\section{Gili Gede}

Pengambilan sampel tutupan terumbu karang hidup di Gili Gede disebelah barat Gili Gede. Tutupan karang hidup di Gili Gede termasuk dalam kondisi rendah yaitu 23,8\% tutupan karang hidup. Pada saat pemantauan Acropora Branching yang banyak ditemukan yaitu $19,6 \%$ selain itu yaitu karang jenis non acropora yang luas tutupannya dibawah 2\%. Sedangkan tutupan karang mati yaitu 58,2\% dengan karang mati yang ditumbuhi dengan algae sebesar $40,8 \%$ sisanya $17,4 \%$ yaitu patahan karang.

\section{Gili Layar}

Pengambilan sampel tutupan karang hidup di Gili Layar diambil pada utara pulau. Pengambilan sampel dilakukan pada satu titik pengamatan saja.
Hasil yang didapat yaitu tutupan karang hidup di perairan Gili Layar sebesar 9,2\% atau kondisinya dalam tipe rendah. Jenis Acropora Branching dan Acropora Submasive besaran tutupannya yaitu 4,2\% dan 0,4\%. Sedangkan jenis karang non-acropora yaitu tipe Coral Massive dan Coral Mushroom sebesar 3\% dan $1,6 \%$. Tutupan karang mati di Gili Layar yaitu $34,2 \%$ dengan $29,2 \%$ karang mati dengan ditumbuhi algae, 2,2\% karang mati, dan 2,8\% patahan karang. Di Gili Layar, tutupan yang mendominasi yaitu soft coral (karang lunak) sebesar 43,2\%.

\section{Gili Asahan}

Pengambilan sampel tutupan karang hidup di Gili Asahan diambil pada utara pulau. Pengambilan sampel dilakukan pada satu titik pengamatan saja. Hasil yang didapat yaitu tutupan karang hidup di perairan Gili Layar sebesar $26,2 \%$ atau kondisinya dalam tipe sedang. Jenis Acropora Branching, Acropora Tabulate, Acropora Submassive, dan Acropora Digitate ditemukan di Gili Asahan. Besaran tutupannya secara berurut yaitu $0,8 \%, 2 \%, 15,4 \%$ dan $2 \%$. Sedangkan jenis karang non-acropora yaitu tipe Coral Massive dan Hard Coral sebesar 3,4\% dan 2,6\%. Tutupan karang mati di Gili Asahan yaitu 45\% dengan 
20,6\% karang mati dengan ditumbuhi algae $3,6 \%$ karang mati, dan $20,8 \%$ patahan karang. Pada perairan Gili Asahan, tutupan karang tipe lifeform jenis yang lain juga banyak ditemukan diantaranya yaitu sponge sebesar 3,8\%, soft coral (karang lunak) sebesar 4\%, dan turf algae sebesar $6,2 \%$.

Tabel 4. Persentase tutupan terumbu karang Gili Gede

\begin{tabular}{|c|c|c|c|}
\hline & Jenis & Lifeform & Gili Gede (\%) \\
\hline \multirow[t]{9}{*}{ Karang Hidup } & Acropora & $\mathrm{ACB}$ & 19,6 \\
\hline & & $\mathrm{ACT}$ & \\
\hline & & ACS & \\
\hline & & $\mathrm{ACD}$ & \\
\hline & Non-Acropora & $\mathrm{CB}$ & \\
\hline & & $\mathrm{CM}$ & 1,0 \\
\hline & & $\mathrm{HC}$ & 2,0 \\
\hline & & HA & 1,2 \\
\hline & & CMR & \\
\hline \multicolumn{3}{|l|}{ Total Karang Hidup } & 23,8 \\
\hline \multirow[t]{3}{*}{ Karang Mati } & Death Coral & DC & \\
\hline & Death Coral With Algae & DCA & 40,8 \\
\hline & Rubble & $\mathrm{R}$ & 17,4 \\
\hline \multicolumn{3}{|c|}{ Total Karang Mati } & $\mathbf{5 8 , 2}$ \\
\hline \multirow[t]{3}{*}{ Fauna Lain } & Sponge & SP & 1,0 \\
\hline & Soft Coral & $\mathrm{SC}$ & \\
\hline & Other & OT & \\
\hline \multirow[t]{2}{*}{ Alga } & Algae Assamble & AA & \\
\hline & Turf Algae & TA & \\
\hline \multirow[t]{2}{*}{ Abiotik } & Rock & $\mathrm{RCK}$ & \\
\hline & $\mathrm{S}$ & S & 17,0 \\
\hline
\end{tabular}

Tabel 5. Persentase tutupan terumbu karang Gili Layar

\begin{tabular}{llll}
\hline & Jenis & Lifeform & Gili Layar (\%) \\
\hline Karang Hidup & Acropora & ACB & 4,2 \\
& & ACT & \\
& & ACS & 0,4 \\
& Non-Acropora & ACD & \\
& & CB & 3,0 \\
Total Karang Hidup & & CM & \\
Karang Mati & & HC & \\
& Death Coral & HA & 1,6 \\
Total Karang Mati & Death Coral With Algae & DCA & 2,2 \\
& & R & 2,2 \\
& & & $\mathbf{3 4 , 2}$ \\
\hline
\end{tabular}




\begin{tabular}{llll}
\hline Fauna Lain & Sponge & SP & 7,2 \\
& Soft Coral & SC & 43,2 \\
\multirow{4}{*}{ Alga } & Other & OT & \\
\multirow{2}{*}{ Abiotik } & Algae Assamble & AA & \\
& Turf Algae & TA & 4,6 \\
& Rock & RCK & \\
& S & S & 1,6 \\
\hline
\end{tabular}

Tabel 6. Persentase tutupan terumbu karang Gili Asahan

\begin{tabular}{llll}
\hline & Jenis & Lifeform & Gili Asahan (\%) \\
\hline Karang Hidup & Acropora & ACB & 0,8 \\
& & ACT & 2,0 \\
& & ACS & 15,4 \\
& Non-Acropora & ACD & 2,0 \\
& & CB & \\
& & CM & 3,4 \\
Total Karang Hidup & & HC & 2,6 \\
Karang Mati & & HA & \\
& Death Coral & CMR & \\
Total Karang Mati & & $\mathbf{2 6 , 2}$ \\
Fauna Lain & Death Coral With Algae & DC & 3,6 \\
& Rubble & DCA & 20,6 \\
& Sponge & & 20,8 \\
Alga & Soft Coral & SP & $\mathbf{4 5}$ \\
\multirow{2}{*}{ Abiotik } & Other & SC & 3,8 \\
& Algae Assamble & OT & 1,0 \\
& Turf Algae & AA & 0,2 \\
& Rock & TA & 6,2 \\
& S & RCK & \\
& & S & 11,6 \\
\hline
\end{tabular}

\section{Parameter Fisika Kimia}

Kehidupan terumbu karang mempunyai keterkaitan dengan keadaan lingkungan. Kualitas perairan Gili Gede Indah memiliki rata-rata kualitas perairan yang baik untuk pertumbuhan karang. Hasil pengukuran Kualitas perairan saat penelitian di ketiga gili ini memilki kondisi yang hampir relatif sama satu dengan lainnya (dapat dilihat pada Tabel 7).

Tabel 7. Kualitas air laut di ketiga gili

\begin{tabular}{llll}
\hline \multicolumn{1}{c}{ Parameter } & \multicolumn{1}{c}{$\begin{array}{c}\text { Stasiun 1 } \\
(\text { Gili Gede) }\end{array}$} & $\begin{array}{c}\text { Stasiun 2 } \\
(\text { Gili Layar) }\end{array}$ & $\begin{array}{c}\text { Stasiun 3 } \\
(\text { Gili Asahan) }\end{array}$ \\
\hline Salinitas $(\% 00)$ & 31 & 32 & 32 \\
Temperatur $\left({ }^{\circ} \mathrm{C}\right)$ & 29,8 & 29,6 & 30,2 \\
Kecerahan $(\%)$ & 100 & 100 & 100 \\
Kecepatan Arus (m/s) & 4,66 & 4,43 & 4,82 \\
Kedalaman (m) & $3,8-4,5$ & $4,7-5,6$ & $4-6$ \\
Oksigen Terlarut (mg/l) & 8,6 & 8,4 & 8,7 \\
\hline
\end{tabular}


Salinitas di ketiga gili tersebut berkisar antara 31 - 32 ppt, dimana kondisi tersebut masih dalam kondisi yang optimum untuk kehidupan terumbu karang. Termperatur di ketiga gili tersebut yaitu $29,6-30,2{ }^{\circ} \mathrm{C}$, sedangkan oksigen terlarut atau oksigen yang ada di perairan yaitu $8,4-8,7 \mathrm{mg} / \mathrm{l}$. Nilai oksigen terlarut di ketiga lokasi pengamatan cukup tinggi diduga karena banyaknya pertumbuhan lamun di lokasi penelitian. Kondisi ini didukung oleh penelitian Wyzer, dkk. 2018, mengatakan nilai oksigen terlarut berdasarkan hasil analisis laboratorium untuk perairan laut Pulau Mansinam antara 6,12 - 9,33 $\mathrm{mg} / \mathrm{L}$. Nilai ini memenuhi baku mutu yang ditetapkan sebagai kawasan wisata bahari. Tingginya nilai DO diduga pada lokasi penelitian tersebut didapati adanya pertumbuhan lamun yang cukup banyak. Kondisi temperatur dan oksigen terlarut dengan kondisi yang dipaparkan merupakan kondisi yang optimum untuk kehidupan dan pertumbuhan karang (Thovyan et al, 2017).

Dari hasil pemantauan di lapangan kerusakan terumbu karang di Desa Gili Gede Indah tidak lepas dari kegiatan wisata dan aktivitas nelayan atau pemancing. Pada saat melakukan penelitian terlihat jelas kerusakan karang diakibatkan oleh aktivitas yang dilakukan para pemancing yang berjalan hingga ke tengah laut karena pada saat siang menuju sore hari kondisi air laut surut. Waktu tersebut dilakukan untuk melakukan pemancingan hingga ke tengah laut yang berdampak ke karang akibat terinjaknya oleh pemancing.

Terlihat dari pemantauan pada saat penelitian persentase patahan karang cukup tinggi yaitu 2,8 - 20,8\% sebaran di ketiga gili tersebut. Perlu adanya sosialisasi kepada masyarakat setempat untuk melakukan pemancingan tanpa adanya pengerusakan karang dengan melihat pijakan agar tidak terjadi kerusakan karang akibat injakan dari pemancing. Selain itu bisa dengan membuat penentuan spot-spot pemancingan yang diizinkan. Hal tersebut bisa mengurangi dampak kerusakan yang meluas akibat tidak terkoordinirnya para pemancing yang ada di ketiga gili tersebut.

\section{KESIMPULAN}

Validasi citra satelit sentinel 2A menunjukkan bahwa hasil interpretasi citra memiliki akurasi yang cukup tinggi yaitu $70,52 \%, 82 \%$, dan $88 \%$. Kondisi tutupan terumbu karang di ketiga gili tersebut memiliki kategori rendah - sedang, yaitu 9,2 - 26,2 \%. Sedangkan kondisi kualitas air yang ada di ketiga gili tersebut memiliki kondisi yang optimum untuk kehidupan dan pertumbuhan karang. Kerusakan karang diakibatkan oleh aktivitas wisata dan masyarakat yang dianggap merusak yang perlu dikelola dan dikaji untuk mengurangi kerusakan tersebut.

\section{DAFTAR PUSTAKA}

Alamsyah. R, Uspar, Nurfadillah. (2019). Sebaran dan Luasan Terumbu Karang di Perairan Pulau Larearea Menggunakan Citra Landsat 8. Prodi Sumber Daya Perairan. STIP Muhammadiyah Sinjai

Bachtiar I, Wildan (Editors). (2018). Ekosistem Pesisir di Teluk Sekotong Kabupaten Lombok Barat. COREMAP-CTI. Jakarta: Lembaga Ilmu Pengetahuan Indonesia. Pp. 68

Bennet, M.K., Nicolas, Y.W., dan Karen, J. (2020). Automating Drone Image Processing to Map Coral Reef Substrates Using Google Earth Engine. MDPI. Drones. Australia 
English, S., Wilkinson, C. dan Barker, V. (1994). Survey Manual for Tropical Marine Resources. Australian Institut of Marine Science. Townsville-Australia. $368 \mathrm{hlm}$

Irawan J, Bandi, S, Andri, S. (2017). Pemetaan Sebaran Terumbu Karang Dengan Metode Algoritma Lyzenga Secara Temporal Menggunakan Citra Landsat 5, 7, dan 8 (Studi Kasus: Pulau Karimunjawa). Jurnal Geodesi Undip. Semarang

Kepmen. LH No. 51 Tahun 2004 Tentang Baku Mutu Air Laut: https://ppkl.menlhk.go.id/ (diakses pada 22 Januari 2022)

Kushardono, D. (2017). Klasifikasi Digital Pada Penginderaan Jauh. IPB Press. Kota Bogor. Indonesia

Lillesand, T.M., Kiefer, R.W. (1979). "Remote Sensing and Image Interpretation", John Wiley \& Sons. lnc., Canada.

Littaqwa, L. A. A. (2013). Asosiasi Nudibranchia Pada Ekosistem Terumbu Karang di Perairan Gili Meno Pulau Lombok. Prodi Ilmu Kelautan. Universitas Padjadjaran.

Nybakken, J.W. (1992). Biologi Laut: Suatu Pendekatan Ekologis. PT. Gramedia Pustaka Utama, Jakarta
Rudiyanto, A. (2020). Pengaruh Covid19 terhadap Tujuan Pembangunan Berkelanjutan. Disampaikan pada Webinar Sustainability Talk: Menjaga Momentum Pencapaian SDGs Pasca-Corona. 8 Mei 2020

Supriharyono, (2000). Pelestarian dan Pengelolaan Sumber Daya Alam di Wilayah Pesisir Tropis. PT Gramedia Pustaka Utama, Jakarta.

Susilo, S. B. (2017). Penginderaan Jarak Jauh "Ocean Color". PT. Penerbit IPB Press. Jalan Taman Kencana No. 3 Bogor 16128. Kota Bogor

Thovyan, A., Sabariah, V., \& Parenden, D. (2017). Percent Cover Coral Reef at Pasir Putih Waters in Manokwari Regency. Jurnal Sumberdaya Akuatik Indopasifik, 1(1), 67-80. Doi: https://10.30862/jsaifpik-unipa.2017.Vol.1.No.1.22

Wyzer, J. I., Hartini, S., \& Tokede, M. J. (2019). Sanitasi Pantai dan Kualitas Perairan Pulau Mansinam pada Kondisi Arus Permukaan Monsun Timur. Cassowary, 1(1), 1-20. https://doi.org/10.30862/casssowary.cs.v1.i1.1

Yosephine. T.H, et al. (1998). Buku Panduan Entri Data Terumbu Karang. Jakarta. LIPI 